\title{
Jaringan Syaraf Tiruan dalam Memprediksi Penjualan Air Minum dalam Kemasan dengan Metode Backpropogation
}

\author{
Hafiz Pratama1, Poningsih ${ }^{2}$, Jalaluddin ${ }^{3}$ \\ STIKOM Tunas Bangsa Pematangsiantar \\ pratamahafiz1200@gmail.com,poningsih@amiktunasbangsa.ac.id, jalaluddin@stikomtb.ac.id
}

\begin{abstract}
This study predicts the sale of bottled water by applying Artificial Neural Networks. The application uses the Backpropogation Algorithm where the data entered is the number of sales, then Artificial Neural Networks are formed by determining the number of each layer. After the network is formed training is carried out from the data that has been grouped. Experiments are carried out with a network architecture consisting of input units, hidden units, output units and network architecture. Testing is done with Matlab software. Predictions with the best accuracy use 3-10-1 architecture with an accuracy rate of $75 \%$ and the lowest level of accuracy using architecture 3-40-1 with an accuracy rate of 33\%.
\end{abstract}

Keywords : Artificial Neural Networks, Sales, Prediction, Backpropogation, Matlab.

Abstrak - Penelitian ini memprediksi penjualan air minum dalam kemasan dengan menerapkan Jaringan Syaraf Tiruan. Penerapannya menggunakan Algoritma Backpropogation dimana data yang dimasukkan adalah jumlah penjualan, kemudian dibentuk Jaringan Syaraf Tiruan dengan menentukan jumlah setiap lapisan. Setelah jaringan terbentuk dilakukan training dari data yang telah di kelompokkan tersebut. Percobaan dilakukan dengan arsitektur jaringan yang terdiri dari unit masukan, unit tersembunyi, unit keluaran dan arsitektur jaringan. Pengujian dilakukan dengan perangkat lunak Matlab. Prediksi dengan tingkat akurasi terbaik menggunakan arsitektur 3-10-1 dengan tingkat akurasi sebesar 75\% dan tingkat akurasi terendah menggunakan arsitektur 3-40-1 dengan tingkat akurasi sebesar 33\%.

Kata Kunci : Jaringan Syaraf Tiruan, Penjualan, Prediksi, Backpropogation, Matlab.

\section{PENDAHULUAN}

Perencanaan kapasitas penjualan yang baik harus sesuai dengan besarnya kebutuhan permintaan. Perusahaan akan mengalami kerugian apabila hasil produksi dengan hasil penjualan tidak sesuai, apabila jumlah air yang diproduksi jumlahnya lebih sedikit daripada yang dibutuhkan akibatnya kebutuhan konsumen tidak dapat dipenuhi yang menuntun kepada kekecewaan konsumen. Tidak adanya perhitungan merupakan salah satu penyebab perusahaan memproduksi air yang sangat berlebih setiap bulannya bahkan sampai kurang karena tidak bisa mengimbangi penjualan. Disini penulis akan memberikan perhitungan untuk memprediksi penjualan air di masa mendatang yang dapat digunakan untuk menentukan jumlah penjualan berdasarkan data sebelumnya. Jaringan Syaraf Tiruan Backpropagation merupakan sebuah metode yang dapat digunakan sebagai metode prediksi jumlah penjualan air minum dalam kemasan. Konsepnya adalah data dari periode lalu dimasukkan kedalam sistem kemudian dilakukan proses pelatihan menggunakan Jaringan Syaraf Tiruan dengan metode Backpropagation. 


\section{METODOLOGI PENELITIAN}

Kecerdasan Buatan atau atificial intelligent adalah salah satu cabang Ilmu pengetahuan berhubungan dengan pemanfaatan mesin untuk memecahkan persoalan yang rumit dengan cara yang lebih manusiawi [1]-[3]. Jaringan Syaraf Tiruan (JST) merupakan suatu sistem pemrosesan informasi yang mempunyai karakteristik menyerupai Jaringan Syaraf Biologis (JSB). Jaringan Syaraf Tiruan tercipta sebagai suatu generalisasi model matematis dari pemahaman manusia (human cognition). Backpropagation merupakan salah satu metode pelatihan dari Jaringan Syaraf Tiruan. Backpropagation menggunakan arsitektur multilayer dengan metode pelatihan supervised training. Prediksi adalah proses untuk memperkirakan berapa kebutuhan dimasa yang akan datang yang meliputi kebutuhan dalam ukuran kuantitas, kualitas, waktu dan lokasi yang dibutuhkan dalam rangka memenuhi permintaan barang ataupun jasa [4]-[10].

\subsection{METODE PENGUMPULAN DATA}

a. Studi Literatur, Melakukan penelitian dan pembelajaran terhadap referensireferensi yang berhubungan dengan penelitian seperti jurnal-jurnal yang berhubungan atau buku-buku tentang Jaringan Saraf Tiruan, atau melalui situssitus di internet dalam menyelesaikan penelitian ini.

b. Pengumpulan data, data-data diperoleh dari CV.SURYA RAJA TAWON yang berada di JL. SERAM BAWAH N0.28 PEMATANGSIANTAR. Dalam mengumpulkan data dilakukan observasi yaitu pengamatan secara langsung di tempat penelitian sehingga permasalahan yang ada dapat diketahui dengan jelas. Kemudian dilakukan interview yang bertujuan untuk mencapai informasi atau data yang dibutuhkan. Selain itu juga dilakukan studi kepustakaan yaitu membaca jurnal dan buku-buku penunjang dalam melakukan analisa terhadap data dan informasi yang tepat.

c. Penentuan Pola, Tahap ini yakni melakukan pemilihan arsitektur agar selanjutnya dapat dilakukan pelatihan dan pengujian data.

d. Pelatihan Data, sudah ditransformasi dan pola sudah ditentukan selanjutnya dilakukan pelatihan data menggunakan software Matlab.

Tabel 1 Data Penjualan CV. Surta Mas Raja Tawon Pematangsiantar

\begin{tabular}{|l|c|c|c|c|}
\hline \multicolumn{1}{|c|}{ Bulan } & Produksi 2015 & Produksi 2016 & Produksi 2017 & Produksi 2018 \\
\hline Januari & 201345 & 212456 & 223765 & 186367 \\
\hline Februari & 210490 & 221511 & 232619 & 209389 \\
\hline Maret & 227865 & 238976 & 249086 & 216542 \\
\hline April & 216381 & 227492 & 230583 & 219430 \\
\hline Mei & 219865 & 220975 & 268013 & 200021 \\
\hline Juni & 243540 & 254651 & 226756 & 199490 \\
\hline Juli & 276521 & 287632 & 234783 & 229182 \\
\hline Agustus & 231213 & 242610 & 212733 & 239326 \\
\hline September & 275982 & 253760 & 218463 & 191712 \\
\hline Oktober & 210980 & 221879 & 187991 & 203581 \\
\hline November & 257839 & 268940 & 279051 & 298307 \\
\hline Desember & 216701 & 227812 & 238923 & 256980 \\
\hline
\end{tabular}

Pada tabel 3.1 diatas merupakan data produksi air minum tahun 2015 sampai dengan tahun 2018 pada CV. MAS RAJA TAWON, Jln. Seram Bawah No.28 Pematangsiantar yang digunakan pada penelitian ini. 


\subsection{Tahapan Penelitian}

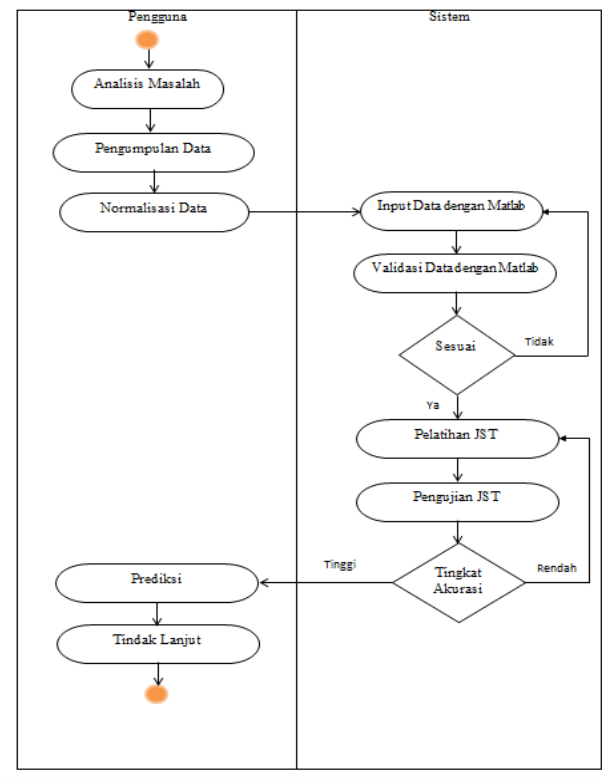

Gambar 1. Tahapan penelitian

Pada gambar di atas merupakan alur aktivitas yang dilakukan penelitian pada sistem yang digunakan. Penulis/pengguna mengidentifikasi masalah dan tujuan penelitian yang dilakukan, mengumpulkan data menggunakan data kuantitatif yang diberikan pihak CV. SURYA MAS RAJA TAWON, kemudian memvalidasi data menggunakan aplikasi Matlab mengukur target error. Hasil dari informasi yang diberikan aplikasi Matlab maka penulis membuat pola Jaringan Syaraf Tiruan dan analisa yang telah dilakukan perhitungan system Jaringan Syaraf Tiruan proses data dan pelatihan kemudin proses data pengujian menggunakan metode Backpropagation dengan menginisialisasi, mengaktivasi dan menghitung bobot pelatihan dengan error terkecil dan kemudian proses normalisasi.

\section{HASIL DAN PEMBAHASAN}

Normalisasi bertujuan untuk mempermudah dalam melakukan pengolahan data menggunakan software Matlab. Normalisasi menggunakan formula berikut [11]-[24]:

$$
x^{\prime}=\frac{0,8(x-a)}{(b-a)}+0,1
$$

\section{Keterangan:}

$\mathrm{x}^{\prime} \quad$ : Data Transformasi

$\mathrm{x} \quad$ : Data yang akan ditransformasi

a : Data minimum rata-rata

b : Data Maximum rata-rata

Melakukan normalisasi akan membagi data menjadi 2 (dua) yakni, data pelatihan (training)dan data pengujian (testing). Data yang ada di atas dilakukan 
proses normalisasi agar dapat di baca oleh sistem yang di gunakan yaitu matlab $R 2011 b$.

\subsection{Pelatihan Dan Pengujian Data dengan Arsitektur 12-2-1}

Layer masukan menggunakan 12 Neuron, layer tersembunyi 2 neuron serta 1 neuron keluaran.Source code pelatihan backpropagationyang digunakan dengan aplikasi Matlab $R 2011 b$ sebagai berikut:

> net=newff(minmax(P),[12,1],\{'logsig','purelin'\},'traingd');

Perintahini digunakan untuk membentuk jaringan pada backpropagationyang mempunyai 10 neuron hidden dan 1 neuron target.

> net.IW $\{1,1\}$;

Net.IW $\{1,1\}$ bobot pertama yang digunakan untuk bobot hidden.

$>$ net.b $\{1\}$;

Net.b $\{1\}$ bias yang digunakan untuk bias hidden.

$>$ net.LW $\{2,1\}$;

Net.LW $\{2,1\}$ bobot kedua yang digunakan untuk bobot keluaran.

$>$ net.b $\{2\}$;

bias yang digunakan untuk bias keluaran. $>>$ net.trainParam.epochs=10000;

Perintah untuk menentukan jumlah iterasi (epochs) maksimum pelatihan.

$>$ net.trainParam.goal $=0.1$;

Perintah untuk menentukan batas MSE agar iterasi dihentikan.

$>$ net.trainParam. $L r=0.01$;

Perintah yang digunakan untuk menentukan laju pembelajaran (Learning Rate).

$>$ net.trainParam.show $=1000$;

Perintah yang digunakan untuk menampilkan frekuensi perubahan MSE.

$>$ net=train $($ net $, P, T)$

Perintah ini akan memunculkan jaringan hasil pelatihan.

$>>[a, P f, A f, e, P e r f]=\operatorname{sim}($ net $, P,[],[], T)$

Perintah ini digunakan untuk melihat hasil yang dikeluarkan oleh jaringan.

Pelatihan dan pengujian Jaringan Syaraf Tiruan dengan arsitektur 12-2-1 dapat dilihat pada gambar 2 .

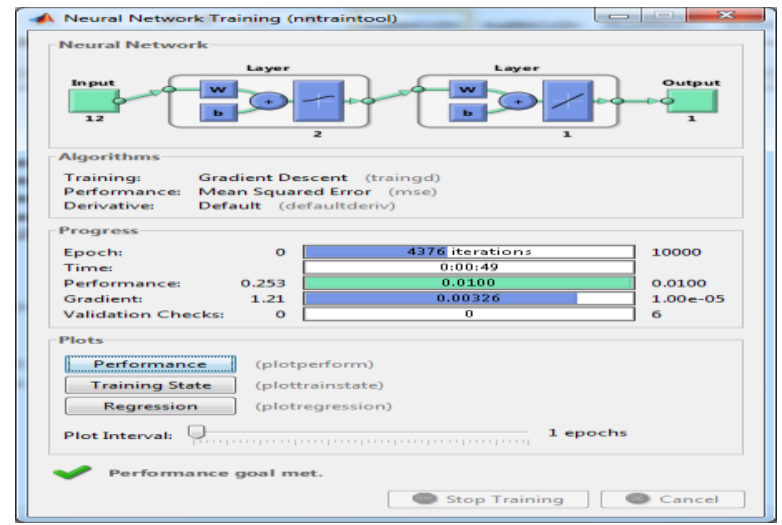

Gambar 2 Pelatihan Menggunakan Arsitektur 12-2-1

Pada gambar 2 terdapat model jaringan dengan arsitektur 12-2-1 menghasilkan epoch sebesar 4376, dengan waktu 00:49 detik. 


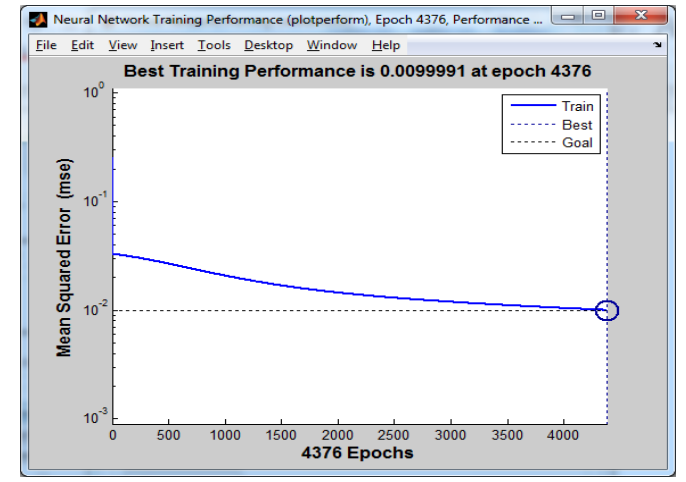

Gambar 3 Performance Pelatihan Menggunakan Arsitektur 12-2-1

Pada gambar 3 menunjukkan error goal (MSE) pada pelatihan ini sebesar 0,0099991 dicapai pada epoch yang ke 4376. Akurasi data pelatihan arsitektur 122-1, dapat dilihat pada tabel 2 .

Tabel 2 Akurasi Data Pelatihan Arsitektur 12-2-1

\begin{tabular}{|c|c|c|c|c|c|}
\hline Bulan & Pola & Target & Output & Error & SSE \\
\hline 1 & pola1 & 0,2030 & 0,1343 & 0,0687 & 0,0047 \\
\hline 2 & pola2 & 0,2870 & 0,364 & $-0,0770$ & 0,0059 \\
\hline 3 & pola3 & 0,4489 & 0,5431 & $-0,0942$ & 0,0089 \\
\hline 4 & pola4 & 0,3424 & 0,2834 & 0,0590 & 0,0035 \\
\hline 5 & pola5 & 0,2820 & 0,3158 & $-0,0338$ & 0,0011 \\
\hline 6 & pola6 & 0,5942 & 0,4846 & 0,1096 & 0,0120 \\
\hline 7 & pola7 & 0,9000 & 0,8484 & 0,0516 & 0,0027 \\
\hline 8 & pola8 & 0,4826 & 0,4416 & 0,0410 & 0,0017 \\
\hline 9 & pola9 & 0,5860 & 0,6181 & $-0,0321$ & 0,0010 \\
\hline 10 & pola10 & 0,2904 & 0,5019 & $-0,2115$ & 0,0447 \\
\hline 11 & pola11 & 0,7267 & 0,5519 & 0,1748 & 0,0306 \\
\hline 12 & pola12 & 0,3454 & 0,4018 & $-0,0564$ & 0,00318 \\
\hline & & & & Jumlah SSE & $\mathbf{0 , 1 2 0 0 2 7 4 0}$ \\
\hline & & & & MSE & $\mathbf{0 , 0 1 0 0 0 2 2 8}$ \\
\hline
\end{tabular}

Pada tabel 2 terdapat pola $1 \mathrm{~s} / \mathrm{d} 12$ adalah pola yang dipakai dalam data pelatihan. Nilai Target diperoleh dari tabel data pelatihan yang sudah dinormalisasi. Nilai Output diperoleh dari rumus $[a, P f, A f, e, P e r f]=\operatorname{sim}(n e t, P,[],[], T)$ yang dimasukkan pada aplikasi Matlab dari input dan data target data pelatihan. Nilai Error diperoleh dari : Target-Output. SSE diperoleh dari : Error^2(^: Pangkat). Jumlah SSE adalah total dari keseluruhan SSE. MSE diperoleh dari : jumlah SSE / 12 (jumlah data). Hasil bernilai Benar apabila nilai SSE $<=0,1$ adalah target error dari pelatihan backpropagation. Berikut akurasi data pengujian arsitektur 12-2-1, dapat dilihat pada tabel 3:

Tabel 3 Akurasi Data Pengujian Arsitektur 12-2-1

\begin{tabular}{|c|c|c|c|c|c|c|}
\hline Bulan & Pola & Target & Output & Error & SSE & Hasil \\
\hline 1 & Pola13 & 0,1000 & 0,3096 & $-0,2096$ & 0,0439 & 1 \\
\hline 2 & Pola 14 & 0,2645 & 0,3711 & $-0,1066$ & 0,0114 & 1 \\
\hline 3 & Pola 15 & 0,3157 & 0,5011 & $-0,1854$ & 0,0344 & 1 \\
\hline 4 & Pola 16 & 0,3363 & 0,2778 & 0,0585 & 0,0034 & 1 \\
\hline 5 & Pola 17 & 0,1976 & 0,3400 & $-0,1424$ & 0,0203 & 1 \\
\hline
\end{tabular}




\begin{tabular}{|c|c|c|c|c|c|c|}
\hline Bulan & Pola & Target & Output & Error & SSE & Hasil \\
\hline 6 & Pola 18 & 0,1938 & 0,4215 & $-0,2277$ & 0,0519 & 1 \\
\hline 7 & Pola 19 & 0,4060 & 0,4882 & $-0,0822$ & 0,0068 & 1 \\
\hline 8 & Pola 20 & 0,4785 & 0,3534 & 0,1251 & 0,0156 & 1 \\
\hline 9 & Pola 21 & 0,1382 & 0,0274 & 0,1108 & 0,0123 & 1 \\
\hline 10 & Pola 22 & 0,2230 & 0,1629 & 0,0601 & 0,0036 & 1 \\
\hline 11 & Pola 23 & 0,9000 & 0,5043 & 0,3957 & 0,1566 & 0 \\
\hline 12 & Pola 24 & 0,6046 & 0,4662 & 0,1384 & 0,0192 & 1 \\
\hline & & & & Jumlah SSE & $\mathbf{0 , 3 7 9 2 8 0 8 2}$ & $\mathbf{9 2 \%}$ \\
\hline & & & & MSE & $\mathbf{0 , 0 3 1 6 0 6 7 4}$ & \\
\hline
\end{tabular}

Dari arsitektur 12-2-1 pada tabel 3 dapat diketahui bahwa tingkat akurasi Pengujian sebesar 92\%. Pola $13 \mathrm{~s} / \mathrm{d} 24$ adalah pola yang dipakai dalam data pengujian. Nilai Target diperoleh dari tabel data pengujian yang sudah dinormalisasi. Nilai Output diperoleh dari rumus $[a, P f, A f, e, P e r f]=\operatorname{sim}(n e t, P,[],[], T)$ yang dimasukkan pada aplikasi Matlab dari input dan target data pengujian. Nilai Errordiperoleh dari : Target-Output. SSE diperoleh dari :Error ${ }^{\wedge} 2$. Jumlah SSE adalah total dari keseluruhan SSE. MSE diperoleh dari : Jumlah SSE / 12 (jumlah data). Hasil bernilai 1 (satu atau benar) apabila nilai SSE $<=0,1$ dan hasil bernilai 0 (nol atau salah) apabila nilai SSE $>0,1$ adalah target error dari pengujian backpropagation. Akurasi (\%) diperoleh dari : Jumlah Benar / $12 * 100$.

\subsection{Perbandingan Akurasi Pola jaringan}

Tabel 4 Kesimpulan Pelatihan dan Pengujian Jaringan

\begin{tabular}{|c|c|c|c|c|c|c|}
\hline \multirow{2}{*}{ No } & \multirow{2}{*}{ Arsitektur } & \multicolumn{3}{|c|}{ Training } & \multicolumn{2}{c|}{ Testing } \\
\cline { 3 - 7 } & & Epoch & Waktu & MSE & MSE & Akurasi \\
\hline 1 & $12-2-1$ & 4376 & $00: 49$ & 0,01000228 & 0,03160674 & $92 \%$ \\
\hline 2 & $12-3-1$ & 8674 & $01: 40$ & 0,01000135 & 0,14296188 & $67 \%$ \\
\hline 3 & $12-4-1$ & 1498 & $00: 18$ & 0,00999387 & 0,12806351 & $58 \%$ \\
\hline 4 & $12-10-1$ & 483 & $00: 06$ & 0,00999796 & 0,07567586 & $42 \%$ \\
\hline 5 & $12-11-1$ & 164 & $00: 02$ & 0,00995542 & 0,06054009 & $75 \%$ \\
\hline
\end{tabular}

Dari 5 pola di atas, Akurasi terbaik yang di peroleh adalah sebesar 92\% dan akurasi terendah adalah $42 \%$. Setelah arsitektur terbaik didapatkan, selanjutnya dilakukan prediksi untuk tahun kedepannya. Berikut tahapan-tahapan dalam melakukan prediksi menggunakan arsitektur 12-2-1.

Tabel 5 Prediksi Tahun 2019

\begin{tabular}{|c|c|c|c|c|}
\hline Bulan & Data Real & Target & Target Prediksi & Prediksi \\
\hline 1 & 186367 & 0,1000 & 0,58340 & 254007 \\
\hline 2 & 209389 & 0,2645 & 0,62660 & 260052 \\
\hline 3 & 216542 & 0,3157 & 0,65030 & 263368 \\
\hline 4 & 219430 & 0,3363 & 0,57750 & 253181 \\
\hline 5 & 200021 & 0,1976 & 0,62630 & 260010 \\
\hline 6 & 199490 & 0,1938 & 0,62860 & 260331 \\
\hline 7 & 229182 & 0,4060 & 0,64830 & 263088 \\
\hline 8 & 239326 & 0,4785 & 0,61410 & 258302 \\
\hline 9 & 191712 & 0,1382 & 0,35110 & 221502 \\
\hline 10 & 203581 & 0,2230 & 0,53080 & 246647 \\
\hline 11 & 298307 & 0,9000 & 0,64940 & 263242 \\
\hline 12 & 256980 & 0,6046 & 0,64590 & 262752 \\
\hline
\end{tabular}


Tabel 5 merupakan tahapan-tahapan melakukan prediksi, Berikut penjelasannnya. Data real adalah data yang diperoleh dari data tahun terakhir. Data target diperoleh dari data Testing yang sudah di normalisasi. Target estimasi pada tabel diperoleh dari hasil pengujian menggunakan software Matlab R2011b, Adapun rumus yang digunakan untuk menetapkan pengujian dengan parameter pada pelatihan ini, dijabarkan sebagai berikut:

$>$ net=newff(minmax(PP),[2,1],\{'logsig','purelin'\},'traingd');

$>$ net.IW $\{1,1\}$;

$>$ net. $\{1\}$;

$>$ net.LW $\{2,1\}$;

$>$ net.b $\{2\}$;

$>$ net.trainParam.epochs $=10000$;

$>$ net.trainParam. $L R=0.1$;

$>$ net.trainParam.goal $=0.01$;

$>$ net.trainParam.show $=1000$;

$>$ net=train(net,PP,TT)

Prediksi ditentukan menggunakan persamaan sebagai berikut:

Prediksi $=\frac{(\text { output }-0,1)(b-a)}{0,8}+a$

\section{KESIMPULAN}

Kesimpulan yang dapat diambil setelah melakukan pelatihan dan pengujian data pada jaringan syaraf tiruan dengan menggunakan algoritma backpropagation adalah sebagai berikut:

1. Pemodelan terbaik pada penelitian ini adalah 12-2-1 dengan menggunakan learning rate 0.01 , MSE pelatihan 0,01000228 , MSE pengujian 0,03160674 , dan mendapatkan tingkat akurasi sebesar $92 \%$. Dengan pola 12-2-1 tersebut selanjutnya dilakukan prediksi untuk tahun 2019 dengan menghasilkan prediksi penjualan tahun 2019 sebanyak 3.066 .482 penjualan.

2. Pemodelan backpropagation dibagi menjadi 2 yaitu model pelatihan dan model pengujian.

\section{DAFTAR PUSTAKA}

[1] A. Wanto and A. P. Windarto, "Analisis Prediksi Indeks Harga Konsumen Berdasarkan Kelompok Kesehatan Dengan Menggunakan Metode Backpropagation,” Jurnal \& Penelitian Teknik Informatika Sinkron, vol. 2, no. 2, pp. 37-44, 2017.

[2] A. Wanto, A. P. Windarto, D. Hartama, and I. Parlina, "Use of Binary Sigmoid Function And Linear Identity In Artificial Neural Networks For Forecasting Population Density," International Journal Of Information System \& Technology, vol. 1, no. 1, pp. 43-54, 2017.

[3] A. Wanto, M. Zarlis, Sawaluddin, and D. Hartama, "Analysis of Artificial Neural Network Backpropagation Using Conjugate Gradient Fletcher Reeves in the Predicting Process," Journal of Physics: Conference Series, vol. 930, no. 1, pp. 1-7, 2017.

[4] S. P. Siregar and A. Wanto, "Analysis of Artificial Neural Network Accuracy Using Backpropagation Algorithm In Predicting Process (Forecasting)," International Journal of Information System \& Technology, vol. 1, no. 1, pp. 34-42, 2017.

[5] J. R. Saragih, M. Billy, S. Saragih, and A. Wanto, "Analisis Algoritma Backpropagation Dalam Prediksi Nilai Ekspor (Juta USD)," Jurnal Pendidikan Teknologi dan Kejuruan, vol. 15, no. 2, pp. 254-264, 2018. 
[6] E. Hartato, D. Sitorus, and A. Wanto, "Analisis Jaringan Saraf Tiruan Untuk Prediksi Luas Panen Biofarmaka di Indonesia," Jurnal semanTIK, vol. 4, no. 1, pp. 49-56, 2018.

[7] S. Setti and A. Wanto, "Analysis of Backpropagation Algorithm in Predicting the Most Number of Internet Users in the World," JOIN (Jurnal Online Informatika), vol. 3, no. 2, pp. 110-115, 2018.

[8] R. E. Pranata, S. P. Sinaga, and A. Wanto, "Estimasi Wisatawan Mancanegara Yang Datang ke Sumatera Utara Menggunakan Jaringan Saraf," Jurnal semanTIK, vol. 4, no. 1, pp. 97-102, 2018.

[9] A. A. Fardhani, D. Insani, N. Simanjuntak, and A. Wanto, "Prediksi Harga Eceran Beras Di Pasar Tradisional Di 33 Kota Di Indonesia Menggunakan Algoritma Backpropagation,” Jurnal Infomedia, vol. 3, no. 1, pp. 25-30, 2018.

[10] J. Wahyuni, Y. W. Paranthy, and A. Wanto, "Analisis Jaringan Saraf Dalam Estimasi Tingkat Pengangguran Terbuka Penduduk Sumatera Utara," Jurnal Infomedia, vol. 3, no. 1, pp. 18-24, 2018.

[11] A. Wanto et al., "Levenberg-Marquardt Algorithm Combined with Bipolar Sigmoid Function to Measure Open Unemployment Rate in Indonesia," in Conference Paper, 2018, pp. 1-7.

[12] I. A. R. Simbolon, F. Yatussa'ada, and A. Wanto, "Penerapan Algoritma Backpropagation dalam Memprediksi Persentase Penduduk Buta Huruf di Indonesia," Jurnal Informatika Upgris, vol. 4, no. 2, pp. 163-169, 2018.

[13] S. P. Siregar, A. Wanto, and Z. M. Nasution, "Analisis Akurasi Arsitektur JST Berdasarkan Jumlah Penduduk Pada Kabupaten / Kota di Sumatera Utara," in Seminar Nasional Sains \& Teknologi Informasi (SENSASI), 2018, pp. 526-536.

[14] A. Wanto, "Optimasi Prediksi Dengan Algoritma Backpropagation Dan Conjugate Gradient Beale-Powell Restarts," Jurnal Teknologi dan Sistem Informasi, vol. 3, no. 3, pp. 370-380, Jan. 2018.

[15] B. K. Sihotang and A. Wanto, "Analisis Jaringan Syaraf Tiruan Dalam Memprediksi Jumlah Tamu Pada Hotel Non Bintang," Jurnal Teknologi Informasi Techno, vol. 17, no. 4, pp. 333346, 2018.

[16] M. A. P. Hutabarat, M. Julham, and A. Wanto, "Penerapan Algoritma Backpropagation Dalam Memprediksi Produksi Tanaman Padi Sawah Menurut Kabupaten/Kota di Sumatera Utara," Jurnal semanTIK, vol. 4, no. 1, pp. 77-86, 2018.

[17] Y. Andriani, H. Silitonga, and A. Wanto, "Analisis Jaringan Syaraf Tiruan untuk prediksi volume ekspor dan impor migas di Indonesia," Register - Jurnal Ilmiah Teknologi Sistem Informasi, vol. 4, no. 1, pp. 30-40, 2018.

[18] A. Wanto, "Penerapan Jaringan Saraf Tiruan Dalam Memprediksi Jumlah Kemiskinan Pada Kabupaten/Kota Di Provinsi Riau," Kumpulan jurnaL Ilmu Komputer (KLIK), vol. 5, no. 1, pp. 61-74, 2018.

[19] I. S. Purba and A. Wanto, "Prediksi Jumlah Nilai Impor Sumatera Utara Menurut Negara Asal Menggunakan Algoritma Backpropagation," Jurnal Teknologi Informasi Techno, vol. 17, no. 3, pp. 302-311, 2018.

[20] A. Wanto, "Prediksi Angka Partisipasi Sekolah dengan Fungsi Pelatihan Gradient Descent With Momentum \& Adaptive LR," Jurnal Ilmu Komputer dan Informatika (ALGORITMA), vol. 3, no. 1, pp. 9-20, 2019.

[21] N. Nasution, A. Zamsuri, L. Lisnawita, and A. Wanto, "Polak-Ribiere updates analysis with binary and linear function in determining coffee exports in Indonesia," IOP Conference Series: Materials Science and Engineering, vol. 420, no. 12089, pp. 1-9, 2018.

[22] A. Wanto, "Prediksi Produktivitas Jagung Indonesia Tahun 2019-2020 Sebagai Upaya Antisipasi Impor Menggunakan Jaringan Saraf Tiruan Backpropagation," SINTECH (Science and Information Technology), vol. 1, no. 1, pp. 53-62, 2019.

[23] B. Febriadi, Z. Zamzami, Y. Yunefri, and A. Wanto, "Bipolar function in backpropagation algorithm in predicting Indonesia's coal exports by major destination countries," IOP Conference Series: Materials Science and Engineering, vol. 420, no. 12089, pp. 1-9, 2018.

[24] A. Wanto et al., "Analysis of Standard Gradient Descent with GD Momentum And Adaptive LR for SPR Prediction," 2018, pp. 1-9. 